\title{
ARE OUR PATIENTS SATISFIED WITH THE CARE RECEIVED WITH THE ERAS (ENHANCED RECOVERY AFTER SURGERY) PROTOCOL IN ELECTIVE COLORECTAL SURGERY?
}

Cabellos Olivares, M; Muñoz Expósito, R; Labalde Martínez, M; Torralba González, M; Rodríguez Fraile, JR; Atance Martínez, JC.

\section{INTRODUCTION}

Enhanced Recovery After Surgery (ERAS) protocols reduce the average of stay and complications, but few studies evaluate the degree of patients satisfaction. The aim of this study was to evaluate it using the satisfaction survey published by the Intensive Pathway of Clinical Recovery in Abdominal Surgery (RICA).

\section{CONCLUSIONS}

$99.16 \%$ of our patients are satisfied with the assistance received and would be operated again according to an ERAS protocol and would recommend it to a friend: There is no relationship between the degree of satisfaction and none of the variables studied.

\section{MATERIAL AND METHODS}

$\rightarrow$ Inclusion criteria: patients undergoing elective colorrectal surgery, $\geq 18$ years old, appropriate cognitive state and ASA I-II-III.

$\rightarrow$ Exclusion criteria: urgent surgery, and existence of higher concomitant surgical processes.

$\rightarrow$ Data analysis: SPSS. Chi-square, Fisher exact test, Student $t$ test. Telephone survey 4 days after hospital discharge to 119 patients (2 patients of the ERAS group died)

\section{RESULTS}

(n 119; 2 patients of the ERAS group died before hospital discharge)

\begin{tabular}{|l|c|}
\hline & ERAS ( $\mathbf{n = 1 2 1 )}$ \\
\hline Age (years) & $68.4 \pm 13.4$ \\
\hline Male & $44(36.7 \%)$ \\
Female & $77(63.6 \%)$ \\
\hline ASA I & $12(9.9 \%)$ \\
ASA II & $66(54.6 \%)$ \\
ASA III & $43(35.5 \%)$ \\
\hline Average stay & $9.8 \pm 3.7$ \\
(days) & \\
\hline
\end{tabular}

\begin{tabular}{|c|c|c|c|}
\hline & $\begin{array}{l}\text { VERY SATISFIED- } \\
\text { SATISFIED }\end{array}$ & $\begin{array}{c}\text { NOT } \\
\text { SATISFIED }\end{array}$ & $p$ \\
\hline $\begin{array}{c}\text { Studies: - No studies or primary studies } \\
\text { - Middle or higher studies }\end{array}$ & $\begin{array}{l}83(69.8 \%) \\
35(29.4 \%)\end{array}$ & $\begin{array}{c}0 \\
1(0.8 \%)\end{array}$ & 0.30 \\
\hline $\begin{array}{r}\text { Hospital room: - Nothing / not adequate } \\
\text { - Adequate/ very good }\end{array}$ & $\begin{array}{l}47(39.5 \%) \\
71(60 \%)\end{array}$ & $\begin{array}{c}0 \\
1(0.8 \%)\end{array}$ & 0.60 \\
\hline Complications: & $\begin{array}{c}82(69 \%) \\
36(31.1 \%)\end{array}$ & $\begin{array}{c}1(0.8 \%) \\
0\end{array}$ & 0.69 \\
\hline Clavien Dindo Complications: $\begin{array}{r}0-1-2 \\
3-4-5\end{array}$ & $\begin{array}{l}93(78.2 \%) \\
25(21 \%)\end{array}$ & $\begin{array}{c}1(0.8 \%) \\
0\end{array}$ & 0.79 \\
\hline Postoperative nausea and vomiting: & $\begin{array}{l}79(66.4 \%) \\
39(32.8 \%)\end{array}$ & $\begin{array}{c}1(0.8 \%) \\
0\end{array}$ & 0.67 \\
\hline $\begin{array}{l}\text { Relationship with the patient: } \\
\text { - Very good / good } \\
\text { - Regular / bad / very bad }\end{array}$ & $\begin{array}{c}115(96.6 \%) \\
3(2.5 \%)\end{array}$ & $\begin{array}{c}1(0.8 \%) \\
0\end{array}$ & 0.67 \\
\hline $\begin{array}{l}\text { Information received before surgery: } \\
\text { - Very good / good } \\
\text { - Regular / bad / very bad }\end{array}$ & $\begin{array}{c}112(94.1 \%) \\
6(5 \%)\end{array}$ & $\begin{array}{c}0 \\
1(0.8 \%)\end{array}$ & 0.06 \\
\hline $\begin{array}{l}\text { Colorectal cancer } \\
\text { Other diagnoses }\end{array}$ & $\begin{array}{c}106(89.1 \%) \\
12(10.1 \%)\end{array}$ & $\begin{array}{c}0 \\
1(0.8 \%)\end{array}$ & 0.899 \\
\hline $\begin{array}{l}\text { Open surgery } \\
\text { Laparoscopic surgery }\end{array}$ & $\begin{array}{c}75(63 \%) \\
43(36.1 \%)\end{array}$ & $\begin{array}{c}0 \\
1(0.8 \%)\end{array}$ & 0.370 \\
\hline Pain referred by the patient $(0-10): \begin{array}{l}\leq 3 \\
\end{array}$ & $\begin{array}{c}94(79 \%) \\
24(20.2 \%)\end{array}$ & $\begin{array}{c}0 \\
1(0.8 \%)\end{array}$ & 0.210 \\
\hline
\end{tabular}

